\title{
Influence of alumina/MWCNT hybrid nanoparticle additives on tribological properties of lubricants in turning operations
}

\author{
Anuj Kumar SHARMA*, Jitendra Kumar KATIYAR, Shubrajit BHAUMIK, Sandipan ROY \\ Kattankulathur, Tamil Nadu 603203, India \\ Received: 26 September 2016/Revised: 31 October 2017 / Accepted: 17 November 2017 \\ (C) The author(s) 2018. This article is published with open access at Springerlink.com
}

Tribology and Surface Interaction Research Lab, Department of Mechanical Engineering, SRM Institute of Science and Technology

\begin{abstract}
A hybrid lubricant with improved thermal and tribological properties was developed by blending multiwalled carbon nanotubes (MWCNTs) with alumina-based nanoparticles into cutting fluid at fixed volumetric proportions (10:90). The hybrid cutting fluid was prepared in different volumetric concentrations $(0.25,0.75$, and $1.25 \mathrm{vol} \%)$, and the tribological properties and contact angles were measured using pin-on-disc tribometry and goniometry, respectively. The study showed a reduction in wear and friction coefficient with increasing nanoparticle concentration. The cutting fluid performance was investigated using minimum quantity lubrication (MQL) in the turning of AISI 304 stainless steel. Regression models were developed for measuring the temperature and tool flank wear in terms of cutting speed, feed, depth of the cut, and nanoparticle concentration using response surface methodology. The developed hybrid nanolubricants significantly reduced the tool flank wear and nodal temperature by $11 \%$ and $27.36 \%$, respectively, as compared to alumina-based lubricants.
\end{abstract}

Keywords: hybrids; nanolubricants; MQL; MWCNT; tool wear; friction coefficient

\section{Introduction}

In the manufacturing industry, the high heat generation in the machining zone restricts the cutting speed of tools during the dry machining of steel. Hence, the desired surface finish is never fully achieved in high speed machining under dry cutting conditions. Furthermore, the high heat affects the hardness and sharpness of the cutting tools causing premature breakage. To overcome these issues, appropriate cutting fluids need to be included in high-speed machining. Cutting fluids play vital role in cooling and lubricating the cutting tool's work-piece interfaces, and at washing away chips from the machining zone. The conventional way of cooling is effective but their excessive use pollutes the environment and may be hazardous for the human.

To restrict excessive use of conventional cutting fluids MQL/NDM (near dry machining) has appeared to improve the penetration of the lubricant into the machining zone. In this technique, a small quantity of cutting fluid is sprayed into the cutting zone under pressurized air. Maruda et al. [1] showed that the minimum quantity lubrication (MQL) technique is suitable for spraying cutting fluid into the cutting zone. Furthermore, Attanasio et al. [2] used the MQL technique and observed reduction of the wear rate of the cutting tools as compared to dry machining method. Research groups by Maruda et al. [3], Cantero et al. [4] and Klocke et al. [5] showed that the use of the MQL technique improves the surface finish and tool life, and reduces the machining forces. Moreover, Maruda et al. [6] achieved a reduction of $40 \%$ in tool wear using the minimum quantity cooling lubrication (MQCL) technique. A study on the hybridized MQL with cryogenic cooling by Sartori et al. [7] showed

* Corresponding author: Anuj Kumar SHARMA, E-mail: anujkumar.s@ktr.srmuniv.ac.in 
better results compared to conventional flood lubrication technique. According to the authors, MQL can be a viable alternative for wet machining because it may minimize both the manufacturing costs and the environmental hazards.

The conventional fluids have good lubrication properties but their poor thermal properties restrict them to be used as cutting fluids. The thermal conductivity of the conventional fluids, which is related to the heat extraction capability, may increase after mixing particles with sizes in the millimeter to micrometer range. However, the use of micron-sized particles leads to clogging and poor stability of the suspensions. To overcome this, the nanoparticles of the $\mathrm{nm}$ size range have replaced the micron-sized particles, leading to the synthesis of a new generation of fluids called "nanofluids".

Numerous researchers observed an increase in the nanofluid thermal conductivity with an increase in the nanoparticle concentration in a base fluid [8-10]. Furthermore, a $22.4 \%$ increase in thermal conductivity was observed after mixing $6 \% \mathrm{Al}_{2} \mathrm{O}_{3}$ in a base fluid at ambient temperature, as compared to conventional fluids [11]. Yang [12] and Choi et al. [13] also observed an increase of about $200 \%$ and $150 \%$ in thermal conductivity, respectively, when multiwalled carbon nanotubes (MWCNT) were added to the base fluid.

Besides the thermal conductivity of the cutting fluid, the friction between the tool and the work-piece interface plays a critical role in the heat generation of the machining zone. The friction increases the tool tip temperature resulting in decrement of the hardness and sharpness of the tool's cutting edge. Hence, friction affects significantly the surface finish and aggravates the tool wear. Sharma et al. [14] showed that the mixing of nanoparticles with cutting fluid increased the thermal conductivity resulting in increased tool life, whereas the cutting force, surface roughness, and cutting temperature decreased. Studies showed that blending of graphite nanoparticles with base fluid enhances its tribological properties because of the lower friction coefficient [15], while $\mathrm{MoS}_{2}$ and graphite solid lubricants reduce the surface roughness and the cutting force during machining [16]. Researchers also observed improved surface quality and reduction of the tool wear, cutting force, and chip thickness compared to dry and conventional wet machining [17, 18]. Additionally, Amrita et al. [19] showed that MQL method reduced the surface roughness, cutting force, cutting temperature and tool wear by $30 \%, 54 \%$, $25 \%$ and $71 \%$, respectively in comparison to conventional wet machining. Yasar et al. [20] observed a reduction in the temperature of the cutting tool during machining with the use of oil based $\mathrm{TiO}_{2}$ nanofluid. Paras et al. [21] noticed an enhancement of the tribological properties of conventional lubricants after mixing $\mathrm{CuO}$ and alumina nanoparticle additives. Roy and Ghosh [22] found that $1 \mathrm{vol} \%$ of MWCNTs and $3 \mathrm{vol} \%$ of alumina noticeably reduced the specific energy and cutting force. Furthermore, mixing $\mathrm{ZnO}$ and $\mathrm{WS}_{2}$ nanoparticles with conventional lubricants increased the tribological properties [23].

So far, researchers focused on lubricants containing mono-type nanoparticles in machining. Very few studies [8,18, 24-30] have been found on hybrid nanofluids, such as colloidal suspensions enriched with two different types of nanoparticles. A review on hybrid nanofluids by Sarkar and Ghosh [24] indicated that a proper hybridization may be contribute to creating hybrid nanofluids for potential use in heat transfer enhancement. Tansen et al. [25] reported that the addition of a small amount of MWCNT nanoparticles to water-based alumina solution increased its potential as a heat transfer fluid. Furthermore, Nine et al. [26] achieved a significant improvement in thermal conductivity by mixing MWCNT nanoparticles with alumina nanofluids, whereas Ahammed et al. [27] recorded an increase of $88.62 \%$ in convective heat transfer coefficient and a reduction of $4.7^{\circ} \mathrm{C}$ in temperature using alumina-graphene hybrid nanofluids. Zhang et al. [28] used $\mathrm{MoS}_{2}$-CNT hybrid nanofluids in grinding and yielded lower $\mathrm{G}$ ratio and surface roughness compared to $\mathrm{MoS}_{2}$ and CNT nanofluids. Moreover, studies on the hybridization of different types of nanoparticles showed an enhancement in thermophysical [29] and tribological [30] properties of base nanofluids. However, the use of hybrid nanofluids as cutting fluids in machining and in turning operations has not been reported.

In the present study, a hybrid nano-lubricant was developed by mixing MWCNT nanoparticles with alumina-based nanofluids in different nanoparticle 
concentrations $(0.25 \%, 0.75 \%$, and $1.25 \%)$. The optimization of the nanoparticle concentration was performed using response surface methodology (RSM) and regression models for tool wear and temperature dependence were developed. The evaluation of the formed hybrid nanolubricants as cutting fluid in turning of AISI 304 stainless steel was conducted for nodal temperature and tool flank wear using the MQL technique. The results were compared with those from the machining performance of alumina-based nanofluids.

\section{Experimental details}

\subsection{Preparation of nanolubricants}

The base fluid was prepared by mixing $5 \mathrm{vol} \%$ vegetable oil in distilled water. The detergent was used as an emulsifier in $0.5 \mathrm{vol} \%$ concentration to stabilize the emulsion of the base fluid. The hybrid $\left(\mathrm{Al}_{2} \mathrm{O}_{3} / \mathrm{MWCNT}\right)$ nanofluid was prepared by mixing $\mathrm{Al}_{2} \mathrm{O}_{3}$ nanofluid (colloidal suspension containing 23\% of $\mathrm{Al}_{2} \mathrm{O}_{3}$ nanoparticles, $45 \mathrm{~nm}$ in diameter purchased by Alfa Aesar $^{\circledR}$ ) with MWCNT nanoparticles in a volumetric ratio of 90:10 in the base fluid at three volumetric concentrations $(0.25,0.75$, and $1.25 \mathrm{vol} \%)$. The surfactant cetyltrimethylammonium bromide (CTAB) was already added to the suspension by the manufacturer. The prepared nanofluids were kept in an ultrasonicator (Toshiba, India) generating $100 \mathrm{~W}$ ultrasonic pulses at $36 \pm 3 \mathrm{kHz}$ at a stretch for $6 \mathrm{~h}$ until a homogeneous and stable suspension was achieved. A fresh nanocutting fluid sample was prepared for each measurement and was used immediately to avoid possible agglomeration or sedimentation. Figure 1 shows the TEM images of nanofluids verifying the size and monodispersity of the nanoparticles.

\subsection{Thermal conductivity}

The thermal conductivity of the alumina and Al-MWCNT nanofluid samples was measured at five temperatures: $25,35,40,45$, and $50{ }^{\circ} \mathrm{C}$. A transient hot wire apparatus (Decagon Devices, Inc., USA) was used to measure the thermal conductivity and thermal resistivity for the rate of temperature increase of the probe at a constant heating rate. To improve accuracy, a KD2 Pro probe was attached vertically to a table. The minimum amount of nanofluid required for measuring the thermal conductivity was $45 \mathrm{~mL}$. The probe was submerged into the fluid sample for approximately $15 \mathrm{~min}$ prior to the first measurement. To achieve thermal equilibrium successive measurements were done every $15 \mathrm{~min}$. The effect of nanoparticle concentration on the thermal conductivity was also studied.

\subsection{Tribological testing}

The nanofluid samples were tested for their tribological behavior with a pin-on-disc tribometer TR-20 (Ducom, India) with maximum speed and load capacity of $2,000 \mathrm{rpm}$ and $1,000 \mathrm{~N}$, respectively. The experimental set-up is depicted in Fig. 2. A cylindrical pin $(\varphi 3 \mathrm{~mm} \times$ $40 \mathrm{~mm}$ ) and a disc (diameter $155 \mathrm{~mm}$ ) that were used in this experiment were both made of AISI 304 stainless steel. The linear speed and load were kept constant at $1 \mathrm{~m} / \mathrm{s}$ and $40 \mathrm{~N}$, respectively. Each experiment run time was $300 \mathrm{~s}$. The sliding track of pin was changed after each run to ensure the availability of a virgin surface for the next run. The rpm of the disc was varied to maintain constant sliding speed and the disc was cleaned after each run with acetone to remove any debris.
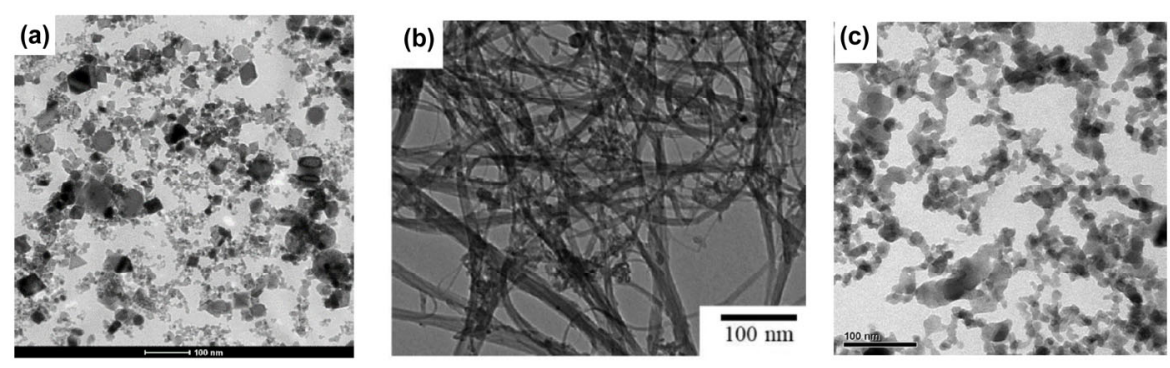

Fig. 1 TEM images of (a) alumina, (b) MWCNT nanofluid, and (c) Al-MWCNT hybrid nanofluid. 

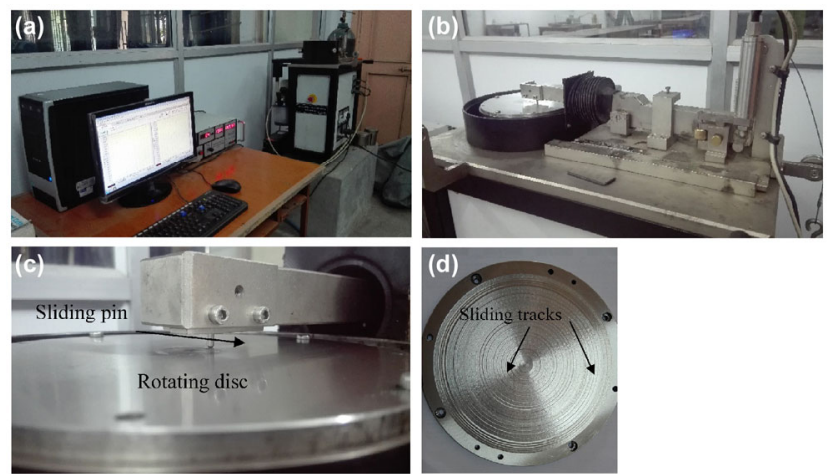

Fig. 2 (a) Pin-on-disc experimental setup; (b) pin and disc machine; (c) closed view of sliding in on rotating disc; (d) sliding tracks on rotating disc.

\subsection{Wettability testing of the nanofluids}

The spreadability of the lubricant over the tool surface enhances the available surface area for the heat extraction on hot tool surfaces. The contact angle measurement is based on the Young's equation (Eq. (1)) [31] which describes an equilibrium force balance at three phase interfaces (solid tool, liquid lubricant, and air) as illustrated in Fig. 3(b). The equilibrium thermodynamic contact angle $(\theta)$ is given by the equation:

$$
\cos \theta=\frac{\sigma_{\mathrm{sv}}-\sigma_{\mathrm{sl}}}{\sigma_{\mathrm{lv}}}
$$

where $\sigma_{\mathrm{lv}}, \sigma_{\mathrm{sv}}$, and $\sigma_{\mathrm{sl}}$ is the liquid-vapor, solid-vapor, and solid-liquid interfacial tensions, respectively.

The contact angle $(\theta)$ was measured at different nanoparticle concentrations (from 0 to $1.5 \%$ ) using a drop shape analyzer 25 (provided by KRUSS), as shown in Fig. 3. The carbide insert was kept on the work-table at ambient temperature and allowed to reach equilibrium at a saturated relatively humid environment. Afterwards, $10 \mu \mathrm{L}$ of the lubricant was carefully dropped through a $0.5 \mathrm{~mm}$ OD needle tip
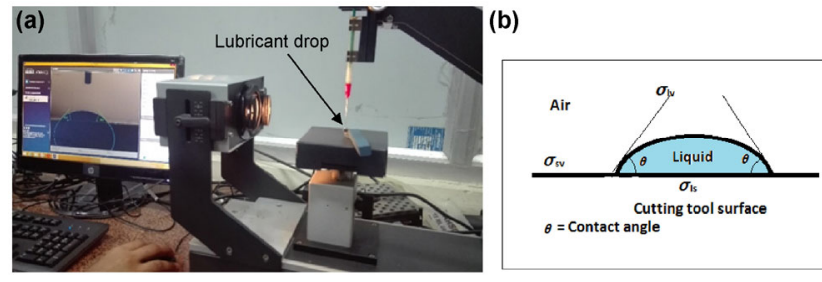

Fig. 3 (a) Contact angle measurement setup; (b) schematic diagram showing a liquid droplet on solid surface. on the top surface of the carbide insert. A camera captured the image of a drop pendant that was formed on the tool surface, and the inbuilt software measured the contact angle. Each experiment was conducted thrice for every sample and their average was considered as the final reading.

\subsection{Experimental set-up of turning}

The turning of AISI 304 stainless steel was performed using the MQL technique on a HMT (model NH 22/1500) lathe machine under mist of alumina and Al-MWCNT nanofluids. A coated cemented carbide insert (Widia's CCMT 09T304-TN2000) was mechanically clamped on a rigid tool holder (widax SCLCR1212F09 D 3J) and was used as cutting tool. The MQL operating fixed parameters included the fluid flow rate at $2.5 \mathrm{~mL} / \mathrm{min}$ and the air supply pressure at 4 bar. A discharge nozzle, capable of impinging mist vertically downward on the tool, was placed at $5 \mathrm{~cm}$ distance above the rake face of the cutting tool (Fig. 4(b)). The mist of the synthesized nanocutting fluid fell naturally on the cutting zone. After each experiment, the carbide insert was removed and dried, and its primary flank wear was evaluated using an Olympus BX51M microscope with a $10 \times$ lens. For better understanding of the process the micrographs had a $200 \mu \mathrm{m}$ scale.

To measure the nodal temperature of the junction
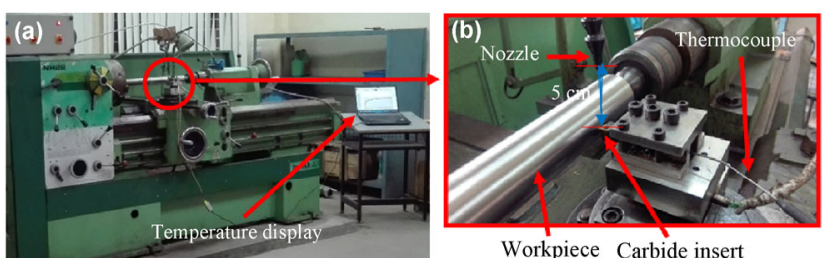

Workpiece Carbide insert
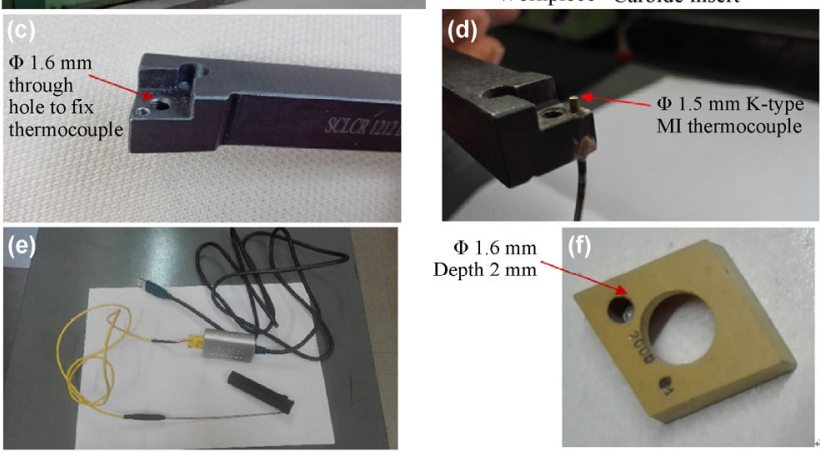

$\Phi 1.6 \mathrm{~mm}$ Depth $2 \mathrm{~mm}$

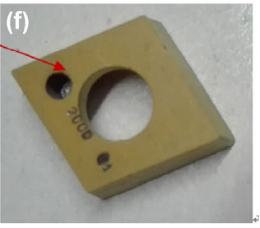

Fig. 4 (a) Turning experimental setup; (b) machining zone close view; (c) tool holder with drilled hole; (d) tool holder fitted with thermocouple; (e) USB TC-01 NI DAQ system; (f) carbide tool insert with drilled hole. 
between the thermocouple and the tool we developed an in-situ set-up consisting of a metal insulated (MI) K-type thermocouple embedded in the tool holder and connected to the computer system through National Instruments data acquisition system USB-TC01 (Fig. 4). To reach closer to the tool tip, a hole of $1.6 \mathrm{~mm}$ diameter was drilled through the tool holder (Fig. 4(c)) and the carbide tool was inserted to a depth of $2 \mathrm{~mm}$ (Fig. 4(f)). The MI K-type thermocouple of sheath diameter $1.5 \mathrm{~mm}$ was inserted and fixed in the tool holder with a silver brazing (Fig. 4(d)). This in-house developed set-up was used to record the nodal temperature during turning operations of the alumina and Al-MWCNT nanofluids. Each experiment was conducted thrice and the average value was considered.

\subsection{Experimental design}

The response surface methodology (RSM) is the collection of statistical techniques used for the modeling and analysis of problems at which one or more responses of interest are influenced by several variables. The RSM focuses on the relationship between multiple independent variables and the response variable $(y)$, expressed as below:

$$
y=f\left(x_{1}, x_{2}, x_{3}, \ldots, x_{k}\right)
$$

where $f$ is a multivariate function and $\left(x_{1}, x_{2}, x_{3}, \ldots, x_{k}\right)$ represent the independent variables (factors). This relationship describes a curved surface known as the response surface. When the first-order lacks in providing an acceptable fit, due to the interaction between the variables and the surface curvature, a second-order model is used to improve the optimization process. A general second-order model is defined as:

$$
y=a_{0}+\sum_{i=1}^{n} a_{i} x_{i}+\sum_{i=1}^{n} a_{i i} x_{i}^{2}+\sum_{i=1}^{n} \sum_{j=1}^{n} a_{i j} x_{i} x_{j}, i<j
$$

where $a_{0}$ is a constant, $a_{i}, a_{\mathrm{ii}}$, and $a_{i j}$ are the coefficient of the first-order (linear), second-order (quadratic), and cross-product terms, respectively, and $x_{i}$ and $x_{j}$ represent the input variables.

The optimization of the input variables were done by RSM using a Box-Behnken design to get the optimized value of the response variables. A total number of 27 trials, including three center points, were employed. All the experiments were performed independently thrice, and the average value of each response was considered. The process variables (input machining parameters) and their values at different levels are listed in Table 1. We used the Design-Expert 10.0 software to design the Box-Behnken experimental set-up, and to perform the regression analysis of the experimental data, build the quadratic model, and plot the three-dimensional response surface plots. The analysis of variance (ANOVA) was evaluated with a statistical analysis of the models. The fitting quality of the second-order polynomial model equation was considered statistically via the determination coefficient $\left(R^{2}\right)$ and the adjusted $R^{2}$. The fitted polynomial equation, expressed by three-dimensional surface plots, was used to evaluate the relationship between the response variables and visualize the interaction between the variables used in this study. A point optimization method optimized the level of each variable for a desirable response. A combination of different optimized input variables, which yielded the desired value of the response, was chosen to verify the validity of the model. Finally, validation experiments tested the adequacy of the experimental set-up. Table 2 shows the experimental design for the alumina and its hybrid nanofluid (alumina-MWCNT) with each run order and the machining performance in terms of the nodal temperature $(T)$ and the tool flank wear (VB).

\section{Results and discussion}

\subsection{Characterization of nanofluids}

Figure 5 shows the thermal conductivity of the nanofluids as a function of temperature at various volumetric concentrations. It was found that the thermal conductivity of all nanofluids increased with increase in both the nanoparticle volumetric concentration and temperature. The highest thermal conductivity was

Table 1 Control factors and their levels.

\begin{tabular}{cccccc}
\hline Control factor & Symbol & Units & Level 1 & Level 2 & Level 3 \\
\hline Cutting speed & $v$ & $\mathrm{~m} / \mathrm{min}$ & 60 & 90 & 120 \\
Feed rate & $f$ & $\mathrm{~mm} / \mathrm{rev}$ & 0.08 & 0.12 & 0.16 \\
Depth of cut & $d$ & $\mathrm{~mm}$ & 0.6 & 0.9 & 1.2 \\
$\begin{array}{c}\text { Nanoparticle } \\
\text { concentration }\end{array}$ & $\mathrm{np}$ & $\mathrm{vol} \%$ & 0.25 & 0.75 & 1.25 \\
\hline
\end{tabular}


Table 2 Experimental results for $T$ and VB using Alumina $\left(\mathrm{Al}_{2} \mathrm{O}_{3}\right)$ and Al-MWCNT hybrid nanofluid.

\begin{tabular}{|c|c|c|c|c|c|c|c|c|}
\hline \multirow{3}{*}{ Run } & \multirow{2}{*}{\multicolumn{4}{|c|}{ Machining parameters }} & \multicolumn{4}{|c|}{ Response variables } \\
\hline & & & & & \multicolumn{2}{|c|}{ Alumina nanofluid } & \multicolumn{2}{|c|}{ Al-MWCNT nanofluid } \\
\hline & $v(\mathrm{~m} / \mathrm{min})$ & $f(\mathrm{~mm} / \mathrm{rev})$ & $d(\mathrm{~mm})$ & $\mathrm{np}(\mathrm{vol} \%)$ & $T\left({ }^{\circ} \mathrm{C}\right)$ & $\mathrm{VB}(\mu \mathrm{m})$ & $T\left({ }^{\circ} \mathrm{C}\right)$ & $\mathrm{VB}(\mu \mathrm{m})$ \\
\hline 1 & 90 & 0.16 & 1.2 & 0.75 & 246.1 & 195.66 & 212.675 & 170.14 \\
\hline 2 & 60 & 0.12 & 1.2 & 0.75 & 201.6 & 176.16 & 191.475 & 153.18 \\
\hline 3 & 120 & 0.12 & 0.9 & 1.25 & 205.4 & 171.72 & 190.65 & 149.32 \\
\hline 4 & 60 & 0.12 & 0.6 & 0.75 & 155.3 & 123.44 & 134.175 & 107.34 \\
\hline 5 & 90 & 0.12 & 0.9 & 0.75 & 190.3 & 151.27 & 164.425 & 131.54 \\
\hline 6 & 60 & 0.12 & 0.9 & 0.25 & 225.3 & 179.13 & 194.675 & 155.74 \\
\hline 7 & 120 & 0.12 & 1.2 & 0.75 & 249.8 & 198.57 & 215.838 & 172.67 \\
\hline 8 & 120 & 0.08 & 0.9 & 0.75 & 183.2 & 125.82 & 167.313 & 133.85 \\
\hline 9 & 90 & 0.08 & 1.2 & 0.75 & 186.7 & 148.42 & 161.325 & 129.06 \\
\hline 10 & 60 & 0.08 & 0.9 & 0.75 & 149.5 & 118.84 & 129.175 & 103.34 \\
\hline 11 & 90 & 0.12 & 0.9 & 0.75 & 185.8 & 147.72 & 160.563 & 128.45 \\
\hline 12 & 120 & 0.12 & 0.9 & 0.25 & 189.4 & 166.06 & 163.7 & 130.96 \\
\hline 13 & 90 & 0.12 & 1.2 & 1.25 & 219.8 & 156.41 & 189.963 & 151.97 \\
\hline 14 & 90 & 0.12 & 0.9 & 0.75 & 197.2 & 156.75 & 170.387 & 136.31 \\
\hline 15 & 60 & 0.16 & 0.9 & 0.75 & 217.5 & 161.93 & 169.9 & 135.92 \\
\hline 16 & 120 & 0.12 & 0.6 & 0.75 & 127.1 & 137.25 & 109.863 & 87.89 \\
\hline 17 & 90 & 0.12 & 0.6 & 0.25 & 142.6 & 113.37 & 123.225 & 98.58 \\
\hline 18 & 90 & 0.08 & 0.6 & 0.75 & 81.5 & 64.82 & 70.4625 & 56.37 \\
\hline 19 & 90 & 0.08 & 0.9 & 0.25 & 168.8 & 134.18 & 145.85 & 116.68 \\
\hline 20 & 90 & 0.08 & 0.9 & 1.25 & 154.2 & 122.57 & 95.725 & 76.58 \\
\hline 21 & 60 & 0.12 & 0.9 & 1.25 & 141.8 & 144.51 & 132.063 & 105.65 \\
\hline 22 & 90 & 0.12 & 1.2 & 0.25 & 231.6 & 184.16 & 200.175 & 160.14 \\
\hline 23 & 90 & 0.12 & 0.6 & 1.25 & 135.9 & 88.06 & 117.463 & 93.97 \\
\hline 24 & 90 & 0.16 & 0.6 & 0.75 & 148.5 & 118.06 & 128.325 & 102.66 \\
\hline 25 & 90 & 0.16 & 0.9 & 1.25 & 207.7 & 165.13 & 179.512 & 143.61 \\
\hline 26 & 90 & 0.16 & 0.9 & 0.25 & 219.9 & 174.81 & 190.012 & 152.01 \\
\hline 27 & 120 & 0.16 & 0.9 & 0.75 & 223.1 & 186.23 & 225.287 & 180.23 \\
\hline
\end{tabular}

observed at the highest temperature $\left(50{ }^{\circ} \mathrm{C}\right)$ at concentration $1.25 \mathrm{vol} \%$ for the Al-MWCNT hybrid nanofluids. It was shown that blending of MWCNT with alumina enhanced the thermal conductivity $(\sim 2.6 \%)$. The obtained results are in good agreement with previous investigations [25, 26, 31].

The images of drop pendants for the alumina and the Al-MWCNT hybrid nanofluids at different concentrations are depicted in Figs. 6 and 7, respectively. The results show that the wettability (expressed as the contact angle) of the nanocutting fluids is affected significantly by the nanoparticle concentration. Specifically, the contact angle of alumina and its hybrid nanofluid decreases and then increases as the nanoparticle concentration increases from 0.25 up to $1.5 \mathrm{vol} \%$. Similarly, Wasan et al. [32] observed an increase in the contact diameter (spreading) of the droplet with increasing nanoparticle concentration in conventional fluids. The smallest contact angle, giving maximum wetting area per unit liquid volume, 


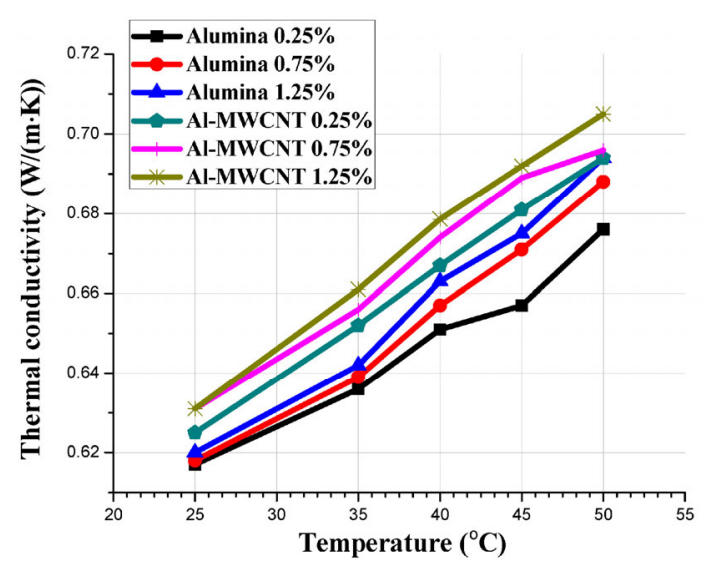

Fig. 5 Thermal conductivity of alumina and Al-MWCNT hybrid nanofluid samples at different temperatures.

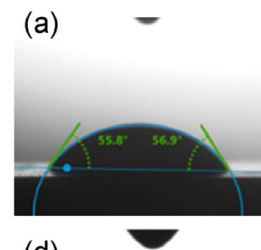

(d)

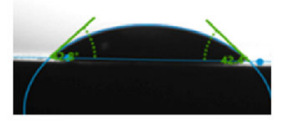

(g)

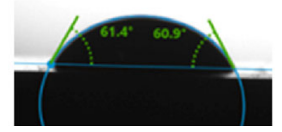

(j)

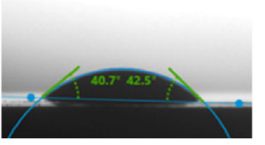

(b)

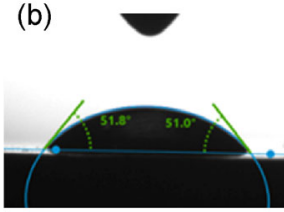

(e)

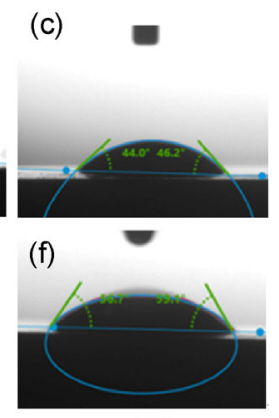

(h)

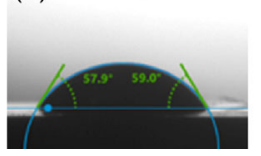

(k) -
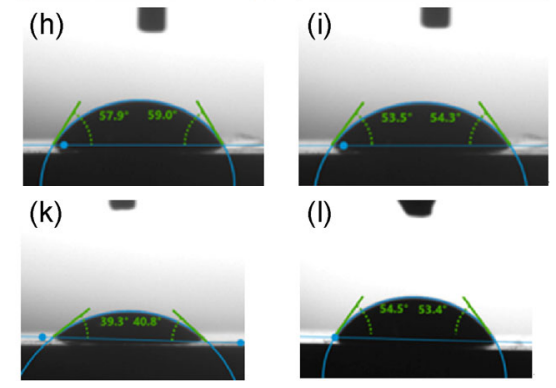

(l)

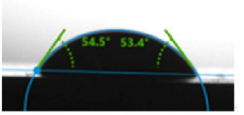

Fig. 6 Examples of drop pendants on carbide tool surface for Alumina nanofluid (a) $0.25 \mathrm{vol} \%$, (b) $0.5 \mathrm{vol} \%$, (c) $0.75 \mathrm{vol} \%$, (d) $1.0 \mathrm{vol} \%$, (e) $1.25 \mathrm{vol} \%$, (f) $1.5 \mathrm{vol} \%$, and for Al-MWCNT hybrid nanofluid (g) $0.25 \mathrm{vol} \%$, (h) $0.5 \mathrm{vol} \%$, (i) $0.75 \mathrm{vol} \%$, (j) $1.0 \mathrm{vol} \%$, (k) $1.25 \mathrm{vol} \%$, (l) $1.5 \mathrm{vol} \%$.

was recorded at $39.5^{\circ}(1.25 \mathrm{vol} \%)$ and $41.9^{\circ}(1.0 \mathrm{vol} \%)$ for the Al-MWCNT and alumina nanofluids, respectively. Hence, the addition of MWCNT to aluminabased nanofluids improved their wettability, and enhanced their heat extraction and lubricating properties. These findings are in good agreement with results obtained previously [31,32]. Figure 8 shows that the Al-MWCNT hybrid nanofluids exhibit lower friction coefficient between the pin and the disc compared to alumina nanofluids. A friction coefficient of approximately 0.07 and 0.18 was measured for

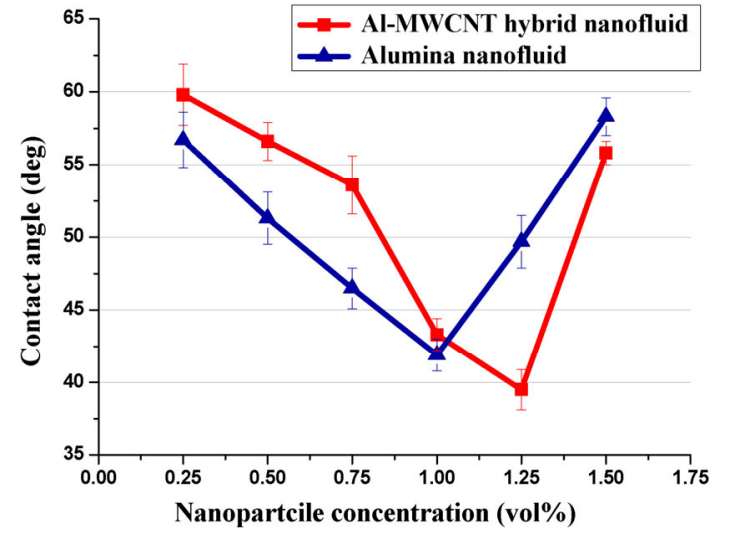

Fig. 7 Contact angle for alumina and Al-MWCNT hybrid nanofluid samples at different concentrations.

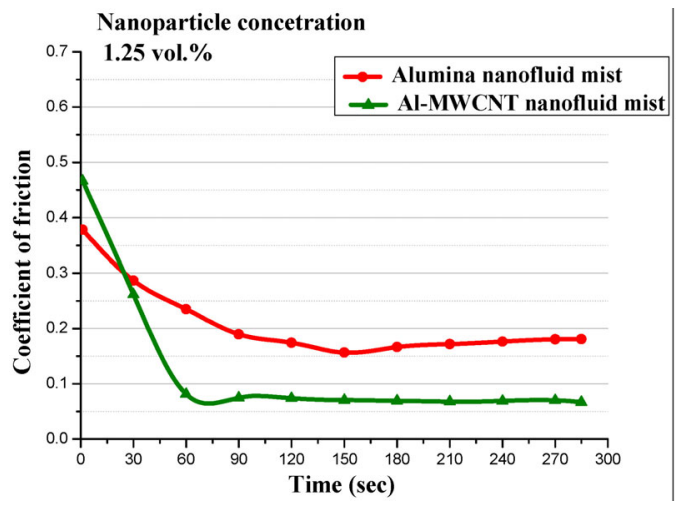

Fig. 8 Variation in coefficient of friction for alumina and Al-MWCNT hybrid nanofluid at 1.25 vol\% concentration as a function of time.

Al-MWCNT and alumina-based nanofluids, respectively, at $1.25 \mathrm{vol} \%$. A lower value of friction coefficient reduces the friction force and therefore reduces the pin wear. The average pin wear was determined as $\sim 481, \sim 273$, and $\sim 198 \mu \mathrm{m}$ for Al-MWCNT hybrid nanofluid and $\sim 494, \sim 403$, and $\sim 387 \mu \mathrm{m}$ for alumina based nanofluids at concentrations $0.25,0.75$ and $1.25 \mathrm{vol} \%$, respectively. The lowest wear value $(\sim 198 \mu \mathrm{m})$ was recorded at $1.25 \mathrm{vol} \%$ for the Al-MWCNT hybrid nanofluids. Moreover, a reduction in wear was observed with increase of the nanoparticle concentration for both, the alumina and its hybrid nanofluids (Fig. 9). This may be attributed to the formation of a nanolayer between the sliding surface of the pin and the disc. Furthermore, the intensity of the mono-layer could be enhanced by the increased number of nanoparticles at higher concentrations. Field emission scanning electron microscope (FESEM) images are shown in Fig. 10 for various nanofluid samples. The images 


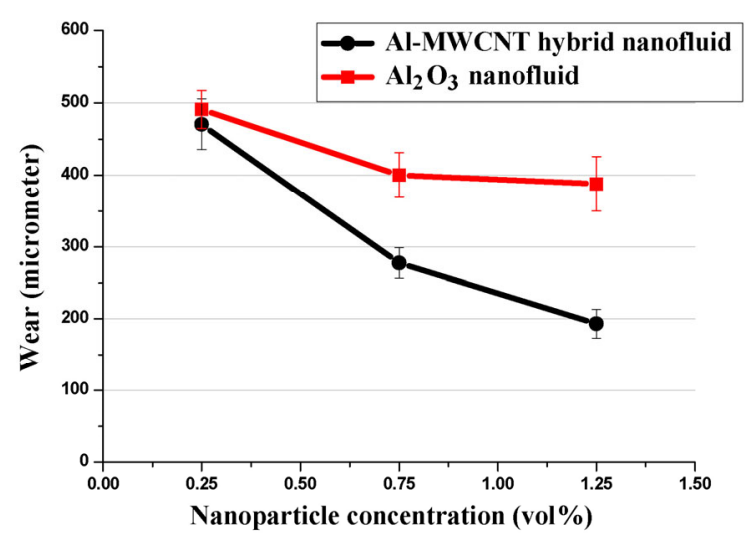

Fig. 9 Wear measurement for alumina and Al-MWCNT hybrid nanofluid samples at different concentrations.

were taken at the sliding surface of the pin during the pin-on-disc experiment with a magnification of $1.00 \mathrm{KX}$. A significant difference in the surface quality was observed for different nanofluids and base fluids. The poor quality surface and the sliding marks are clearly visible at the image of the alumina nanofluid sample. It was also observed that the Al-MWCNT hybrid nanofluids had the smoothest surface, suggesting that the hybrid nanofluids are superior lubricants compared to the alumina nanofluids. Furthermore, improved surfaces were observed at the optimized nanoparticle concentrations for both types of nanofluids (alumina and Al-MWCNT hybrid).

\subsection{Turning of alumina $\left(\mathrm{Al}_{2} \mathrm{O}_{3}\right)$ and alumina- MWCNT mixed nanoparticle nanolubricants}

The variance analysis of the response parameters was done by analyzing the influence of the nanoparticle as included in the obtained results. The analysis was

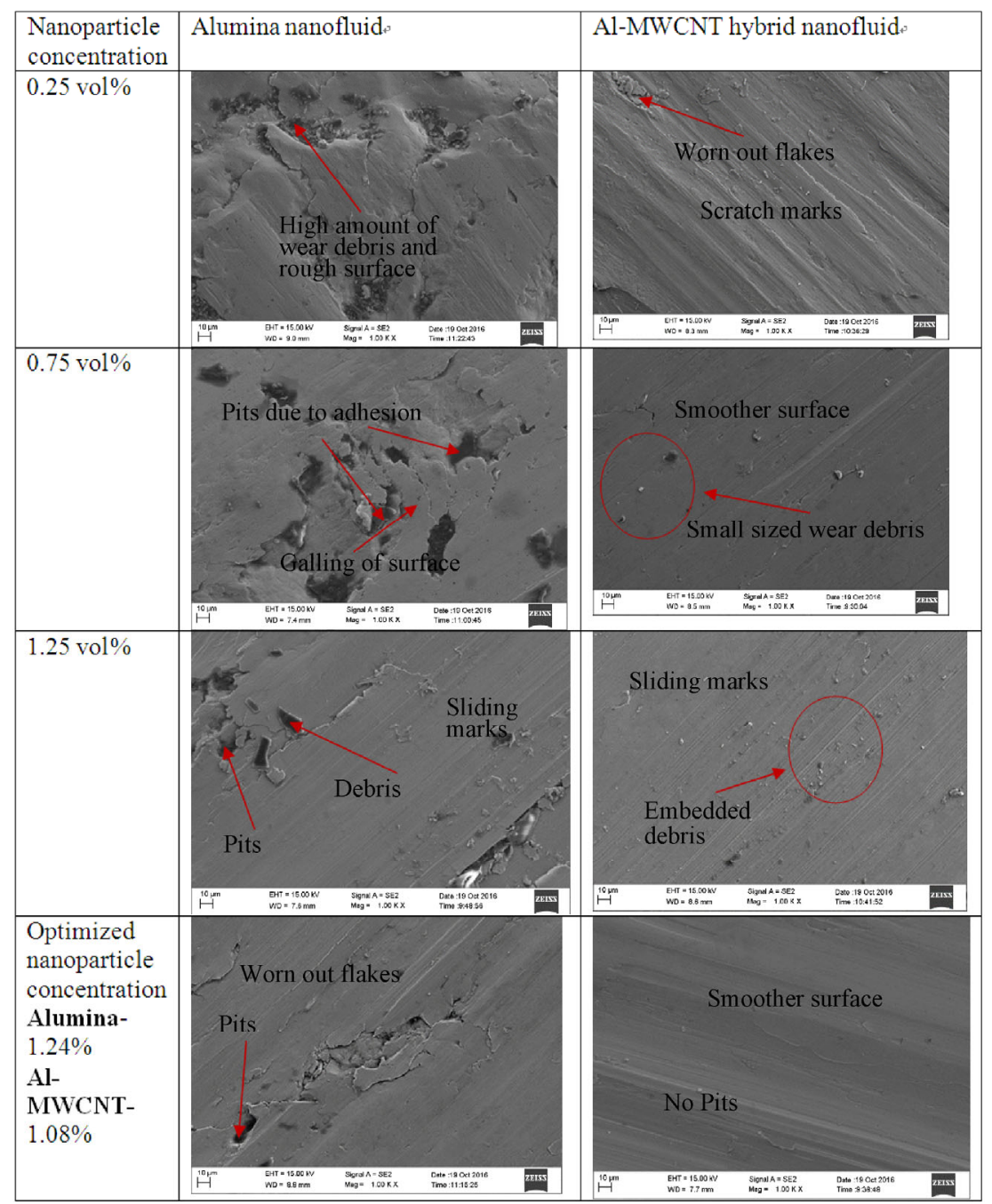

Fig. 10 FESEM images of sliding surface of pins achieved during pin-on-disc tribology testing. 
carried out at a confidence level of $95 \%$, corresponding to a $5 \%$ significance level. Tables 3 and 4 show the ANOVA results of $T$ and $V B$, respectively for the alumina nanofluids. The tables' last column names the influence of the variation of the input variables on the response parameter (output) as "significant" or "non-significant". It was found that the machining input variable $\mathrm{np}$ affects significantly the nodal temperature and the tool flank wear. The ANOVA results for $T$ and VB of the alumina-MWCNT hybrid nanofluids are shown in Tables 5 and 6, respectively. The results clearly indicate that the $\mathrm{np}$ and its interaction with the cutting speed have a significant effect on $T$ and VB.

Table 3 ANOVA table of nodal temperature $(T)$ for Alumina nanofluid.

\begin{tabular}{|c|c|c|c|c|c|c|}
\hline Source & $\begin{array}{l}\text { Sum of } \\
\text { squares }\end{array}$ & DF & $\begin{array}{l}\text { Mean } \\
\text { square }\end{array}$ & F-value & Prob. & Remarks \\
\hline Model & 41779.75 & 14 & 2984.27 & 32.06 & $<0.0001$ & Significant \\
\hline A-v & 630.75 & 1 & 630.75 & 6.78 & 0.0231 & Significant \\
\hline B- $f$ & 9571.10 & 1 & 9571.10 & 102.82 & $<0.0001$ & Significant \\
\hline C- $d$ & 24724.84 & 1 & 24724.84 & 265.62 & $<0.0001$ & Significant \\
\hline D-np & 1060.32 & 1 & 1060.32 & 11.39 & 0.0055 & Significant \\
\hline $\mathrm{AB}$ & 197.40 & 1 & 197.40 & 2.12 & 0.1710 & \\
\hline $\mathrm{AC}$ & 1459.24 & 1 & 1459.24 & 15.68 & 0.0019 & Significant \\
\hline $\mathrm{AD}$ & 2475.06 & 1 & 2475.06 & 26.59 & 0.0002 & Significant \\
\hline $\mathrm{BC}$ & 14.44 & 1 & 14.44 & 0.16 & 0.7006 & \\
\hline $\mathrm{BD}$ & 1.44 & 1 & 1.44 & 0.015 & 0.9031 & \\
\hline $\mathrm{CD}$ & 6.50 & 1 & 6.50 & 0.070 & 0.7960 & \\
\hline $\mathrm{A}^{2}$ & 95.39 & 1 & 95.39 & 1.02 & 0.3314 & \\
\hline $\mathrm{B}^{2}$ & 195.75 & 1 & 195.75 & 2.10 & 0.1726 & \\
\hline$C^{2}$ & 984.04 & 1 & 984.04 & 10.57 & 0.0069 & Significant \\
\hline $\mathrm{D}^{2}$ & 4.36 & 1 & 4.36 & 0.047 & 0.8323 & \\
\hline Residual & 1116.99 & 12 & 93.08 & & & \\
\hline $\begin{array}{l}\text { Lack } \\
\text { of fit }\end{array}$ & 1051.05 & 10 & 105.11 & 3.19 & 0.2623 & $\begin{array}{c}\text { Not } \\
\text { significant }\end{array}$ \\
\hline $\begin{array}{l}\text { Pure } \\
\text { error }\end{array}$ & 65.94 & 2 & 32.97 & & & \\
\hline Cor total & 42896.75 & 26 & & & & \\
\hline
\end{tabular}

Table 4 ANOVA table of tool wear (VB) for Alumina nanofluid.

\begin{tabular}{cccccccc}
\hline Source & $\begin{array}{c}\text { Sum of } \\
\text { squares }\end{array}$ & DF & $\begin{array}{c}\text { Mean } \\
\text { square }\end{array}$ & F-value & Prob. & Remarks \\
\hline Model & 25945.09 & 14 & 1853.22 & 18.88 & $<0.0001$ & Significant \\
A- $v$ & 555.42 & 1 & 555.42 & 5.66 & 0.0348 & Significant \\
B- $f$ & 6872.22 & 1 & 6872.22 & 70.01 & $<0.0001$ & Significant \\
C- $d$ & 14309.23 & 1 & 14309.23 & 145.77 & $<0.0001$ & Significant \\
\hline
\end{tabular}

(Continued)

\begin{tabular}{ccccccc}
\hline Source & $\begin{array}{c}\text { Sum of } \\
\text { squares }\end{array}$ & DF & $\begin{array}{c}\text { Mean } \\
\text { square }\end{array}$ & F-value & Prob. & Remarks \\
\hline D-np & 889.41 & 1 & 889.41 & 9.06 & 0.0109 & Significant \\
AB & 75.00 & 1 & 75.00 & 0.76 & 0.3992 & \\
AC & 18.49 & 1 & 18.49 & 0.19 & 0.6720 & \\
AD & 405.62 & 1 & 405.62 & 4.13 & 0.0648 & \\
BC & 9.00 & 1 & 9.00 & 0.092 & 0.7672 & \\
BD & 0.93 & 1 & 0.93 & 9486 & 0.9240 & \\
CD & 1.49 & 1 & 1.49 & 0.015 & 0.9040 & \\
$\mathrm{~A}^{2}$ & 782.52 & 1 & 782.52 & 7.97 & 0.0154 & Significant \\
$\mathrm{B}^{2}$ & 484.97 & 1 & 484.97 & 4.94 & 0.0462 & Significant \\
$\mathrm{C}^{2}$ & 650.87 & 1 & 650.87 & 6.63 & 0.0243 & Significant \\
$\mathrm{D}^{2}$ & 4.51 & 1 & 4.51 & 0.046 & 0.8340 & \\
Residual & 1177.99 & 12 & 98.17 & & & \\
Lack of & 1136.59 & 10 & 113.66 & 5.49 & 0.1638 & significant \\
fit & & & & & & \\
Pure & 41.39 & 2 & 20.70 & & & \\
error & & & & & & \\
Cor total & 27123.08 & 26 & & & & \\
\hline
\end{tabular}

Table 5 ANOVA table of nodal temperature $(T)$ for Al-MWCNT hybrid nanofluid.

\begin{tabular}{|c|c|c|c|c|c|c|}
\hline Source & $\begin{array}{l}\text { Sum of } \\
\text { squares }\end{array}$ & $\mathrm{DF}$ & $\begin{array}{l}\text { Mean } \\
\text { square }\end{array}$ & F-value & Prob. & Remarks \\
\hline Model & 36797.66 & 14 & 2628.40 & 15.81 & $<0.0001$ & Significant \\
\hline $\mathrm{A}-v$ & 1223.87 & 1 & 1223.87 & 7.36 & 0.0188 & Significant \\
\hline B- $f$ & 9400.30 & 1 & 9400.30 & 56.54 & $<0.0001$ & Significant \\
\hline C- $d$ & 19840.25 & 1 & 19840.25 & 119.32 & $<0.0001$ & Significant \\
\hline D-np & 1050.24 & 1 & 1050.24 & 6.32 & 0.0272 & Significant \\
\hline $\mathrm{AB}$ & 74.39 & 1 & 74.39 & 0.45 & 0.5162 & \\
\hline $\mathrm{AC}$ & 592.31 & 1 & 592.31 & 3.56 & 0.0835 & \\
\hline $\mathrm{AD}$ & 2005.36 & 1 & 2005.36 & 12.06 & 0.0046 & Significant \\
\hline $\mathrm{BC}$ & 10.60 & 1 & 10.60 & 0.064 & 0.8049 & \\
\hline $\mathrm{BD}$ & 392.54 & 1 & 392.54 & 2.36 & 0.1504 & \\
\hline $\mathrm{CD}$ & 4.95 & 1 & 4.95 & 0.030 & 0.8659 & \\
\hline$A^{2}$ & 588.06 & 1 & 588.06 & 3.54 & 0.0845 & \\
\hline $\mathrm{B}^{2}$ & 347.18 & 1 & 347.18 & 2.09 & 0.1741 & \\
\hline $\mathrm{C}^{2}$ & 604.15 & 1 & 604.15 & 3.63 & 0.0809 & \\
\hline $\mathrm{D}^{2}$ & 24.36 & 1 & 24.36 & 0.15 & 0.7086 & \\
\hline Residual & 1995.25 & 12 & 166.27 & & & \\
\hline $\begin{array}{l}\text { Lack } \\
\text { of fit }\end{array}$ & 1946.25 & 10 & 194.63 & 7.94 & 0.1169 & $\begin{array}{c}\text { Not } \\
\text { significant }\end{array}$ \\
\hline $\begin{array}{l}\text { Pure } \\
\text { error }\end{array}$ & 49.00 & 2 & 24.50 & & & \\
\hline Cor total & 38792.91 & 26 & & & & \\
\hline
\end{tabular}


Table 6 ANOVA table of tool wear (VB) for Al-MWCNT hybrid nanofluid.

\begin{tabular}{|c|c|c|c|c|c|c|}
\hline Source & $\begin{array}{l}\text { Sum of } \\
\text { squares }\end{array}$ & DF & $\begin{array}{l}\text { Mean } \\
\text { square }\end{array}$ & F-value & Prob. & Remarks \\
\hline Model & 23371.28 & 14 & 1669.38 & 15.27 & $<0.0001$ & Significant \\
\hline$A-v$ & 732.42 & 1 & 732.42 & 6.70 & 0.0237 & Significant \\
\hline B- $f$ & 6016.19 & 1 & 6016.19 & 55.03 & $<0.0001$ & Significant \\
\hline C- $d$ & 12697.76 & 1 & 12697.76 & 116.15 & $<0.0001$ & Significant \\
\hline D-np & 720.91 & 1 & 720.91 & 6.59 & 0.0246 & Significant \\
\hline $\mathrm{AB}$ & 47.61 & 1 & 47.61 & 0.44 & 0.5218 & \\
\hline $\mathrm{AC}$ & 379.08 & 1 & 379.08 & 3.47 & 0.0872 & \\
\hline $\mathrm{AD}$ & 1171.35 & 1 & 1171.35 & 10.72 & 0.0067 & Significant \\
\hline $\mathrm{BC}$ & 6.79 & 1 & 6.79 & 0.062 & 0.8075 & \\
\hline $\mathrm{BD}$ & 251.22 & 1 & 251.22 & 2.30 & 0.1554 & \\
\hline $\mathrm{CD}$ & 3.17 & 1 & 3.17 & 0.029 & 0.8677 & \\
\hline$A^{2}$ & 352.84 & 1 & 352.84 & 3.23 & 0.0976 & \\
\hline $\mathrm{B}^{2}$ & 213.11 & 1 & 213.11 & 1.95 & 0.1879 & \\
\hline $\mathrm{C}^{2}$ & 374.64 & 1 & 374.64 & 3.43 & 0.0889 & \\
\hline $\mathrm{D}^{2}$ & 20.83 & 1 & 20.83 & 0.19 & 0.6702 & \\
\hline Residual & 1311.81 & 12 & 109.32 & & & \\
\hline $\begin{array}{c}\text { Lack of } \\
\text { fit }\end{array}$ & 1280.45 & 10 & 128.05 & 8.17 & 0.1140 & $\begin{array}{c}\text { Not } \\
\text { significant }\end{array}$ \\
\hline $\begin{array}{l}\text { Pure } \\
\text { error }\end{array}$ & 31.36 & 2 & 15.68 & & & \\
\hline Cor total & 24683.09 & 26 & & & & \\
\hline
\end{tabular}

Equations (4) and (5) represent the regression model of the alumina nanofluids for values of the nodal temperature $(T)$, tool flank wear (VB), coefficient of determination $\left(R^{2}\right)$ and adjusted $R^{2}$ equal to 97.40, 95.66, 95.36, and 90.59, respectively. Moreover, the regression models of the alumina-MWCNT hybrid nanofluids for the values of $T$ and VB with coefficient of determination $\left(R^{2}\right)$ and adjusted $R^{2}$ equal to 98.11 , 96.05, 95.90, 91.44 respectively, are given in Eqs. (6) and (7):

$$
\begin{aligned}
T_{\text {(alumina) }}= & 26.3469-3.05542 \times v+2261.67 \times f \\
& +257.347 \times d-169.425 \times \mathrm{np}-5.85417 \times v \times f \\
& +2.12222 \times v \times d+1.65833 \times v \times \mathrm{np}-158.333 \times f \times d \\
& +30 \times f \times \mathrm{np}-8.5 \times d \times \mathrm{np}+0.00469907 \times v^{2} \\
& -3786.46 \times f^{2}-150.926 \times d^{2}+3.61667 \times \mathrm{np}^{2}
\end{aligned}
$$

$$
\begin{aligned}
& V B_{(\text {alumina })}=-15.571-3.34731 \times v+1798.3 \times f \\
&+332.597 \times d-82.3883 \times \mathrm{np}+3.60833 \times v \times f \\
&+0.238889 \times v \times d+0.671333 \times v \times \mathrm{np}-125 \times f \times d \\
&+24.125 \times f \times \mathrm{np}-4.06667 \times d \times \mathrm{np} \\
&+0.0134588 \times v^{2}-5959.9 \times f^{2}-122.745 \times d^{2} \\
&+3.67667 \times \mathrm{np}^{2} \\
&= \\
& T_{(A l-M W C N T)} \\
&+ 248.212-4.53113 \times v+1337.14 \times f \\
&+3.59375 \times v \times f+1.35208 \times v \times d \\
&+1.49271 \times v \times \mathrm{np}-135.677 \times f \times d \\
&+495.312 \times f \times \mathrm{np}-7.41667 \times d \times \mathrm{np} \\
&+0.0116672 \times v^{2}-5042.64 \times f^{2} \\
&-118.258 \times d^{2}-8.54792 \times \mathrm{np} p^{2} \\
&= 107.57-3.54046 \times v \\
&+1049.71 \times f+196.181 \times d-148.529 \times \mathrm{np} \\
&+2.875 \times v \times f+1.08167 \times v \times d \\
&+1.14083 \times v \times \mathrm{np}-108.542 \times f \times d \\
&+396.25 \times f \times \mathrm{np}-5.93333 \times d \times \mathrm{np} \\
&+0.0090375 \times v^{2}-3950.78 \times f^{2} \\
&+93.125 \times d^{2}-7.905 \times \mathrm{np} p^{2} \\
& V B_{(A l-M W C N T}(6) \\
&
\end{aligned}
$$

The influence of the nanoparticle concentration on the various response variables is shown through the response surfaces, as depicted in Fig. 11 and Fig. 12 for the alumina and Al-MWCNT nanofluids, respectively. Figures $11(\mathrm{a})$ and $11(\mathrm{~b})$ show that the lowest nodal temperature was recorded at the highest $n p \%$ with lowest feed and at the highest $n p \%$ with the lowest depth of cut. Furthermore, the lowest tool wear was observed at a combination of highest $\mathrm{np} \%$ and lowest feed (Fig. 11(c)), and of highest np\% and lowest cutting speed (Fig. 11(d)). Additionally, Figures 12(a) and 12(b) show that the lowest nodal temperature was recorded at a combination of the highest $\mathrm{np} \%$ and lowest feed, and of the highest $\mathrm{np} \%$ with lowest depth of cut using Al-MWCNT hybrid nanofluids. The lowest tool wear was observed with a combination of highest $\mathrm{np} \%$ and lowest feed (Fig. 12(c)) and of highest $\mathrm{np} \%$ and lowest cutting speed (Fig. 12(d)).

\subsection{Optimized input variables for the response parameters}

The optimal values of input machining variables 

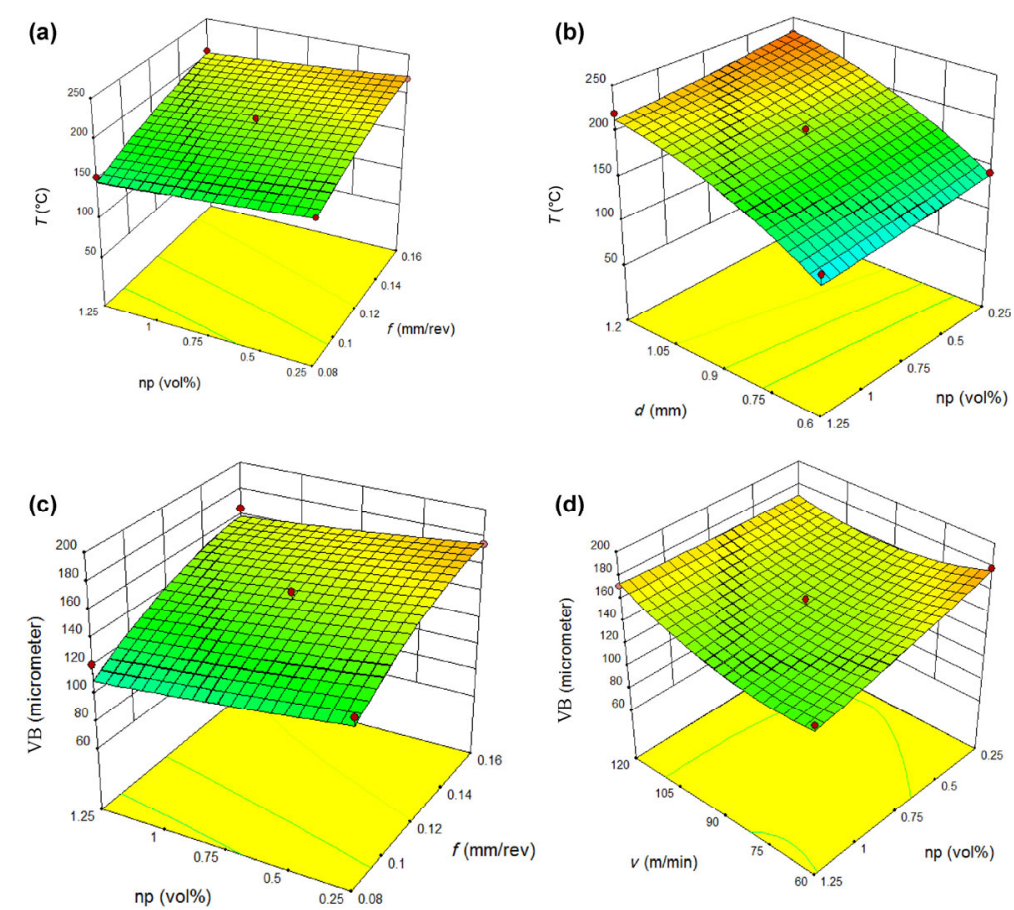

Fig. 11 Estimated response surface plots for $\mathrm{Al}_{2} \mathrm{O}_{3}$ nanoparticle concentration (np) versus $v, f$, and $d$.
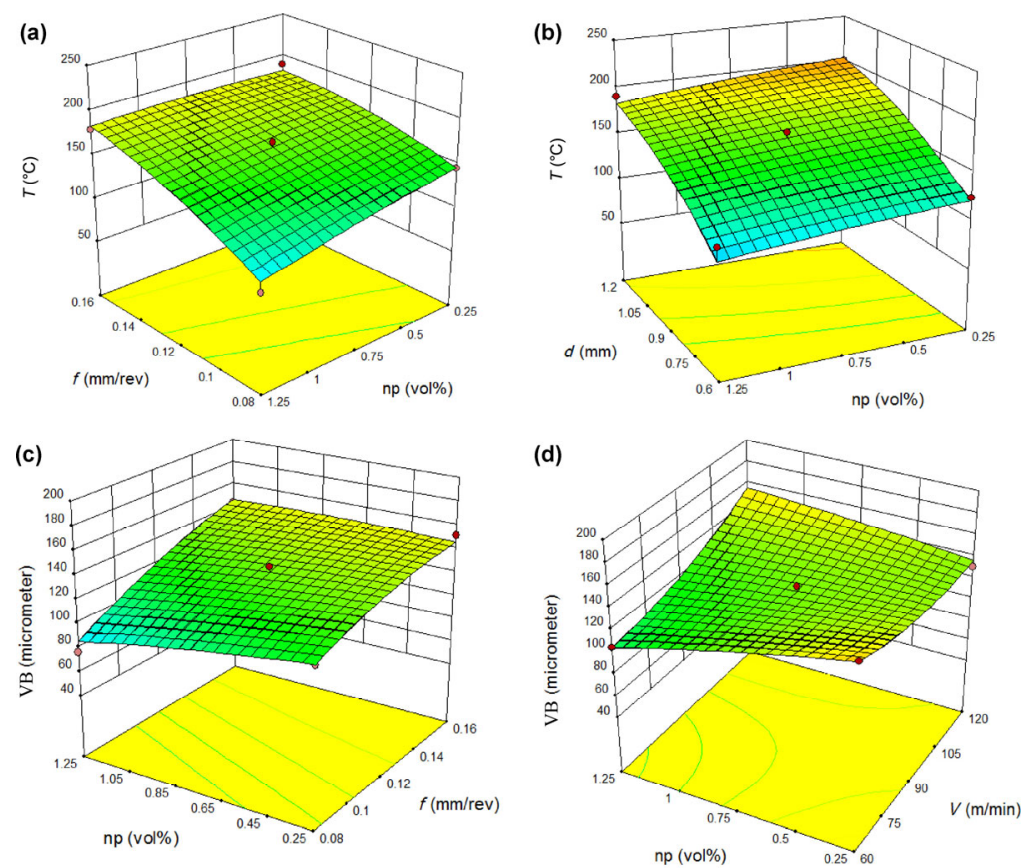

Fig. 12 Estimated response surface plots for Al-MWCNT nanoparticle concentration (np) versus $v, f$, and $d$.

within their predefined range were determined during the turning process by minimizing both response parameters ( $T$ and VB) independently. The goals, the input variables, and the response parameters' minimized values are summarized in Table 7 for the alumina and Al-MWCNT nanofluids.

\subsection{Experimental validation}

The validation of the optimized results was conducted through confirmation runs for the values of the machining input variables $(v, f, d$, and $n p)$ as shown in Table 7. The average response was considered after 
3 runs and compared to the optimized values. The experimental values corresponding to each response parameter are presented in Table 8 . The validation results were in an acceptable range of $\pm 4 \%$ of the optimized values of the response parameters (Table 7). The variation of the validation experiments and the optimized results of $T$ and VB for the alumina nanofluids were recorded at $2.7 \%$ and $1.54 \%$, respectively. However, a variation of $3.00 \%$ and $3.39 \%$ of $T$ and $V B$ was recorded, respectively, for the Al-MWCNT hybrid nanofluids. This verifies that the experimental set-up and regression models were valid for a turning operation in the selected range of parameters selected for the alumina-base and hybrid (Al-MWCNT) nanofluids.

Table 8 shows a significant reduction in the nodal temperature and tool flank wear for the Al-MWCNT hybrid nanofluids compared to the alumina nanofluids. Also, mixing of MWCNT with alumina reduced the temperature from 83.53 to $60.67^{\circ} \mathrm{C}$ and the average tool wear was also reduced from 65.39 to $58.16 \mu \mathrm{m}$.

\subsection{Nodal temperature}

A significant reduction of $27.36 \%$ in nodal temperature with the use of Al-MWCNT hybrid nanofluid may be attributed to the superior thermal conductivity properties of the Al-MWCNT hybrid nanofluids compared to the alumina mixed nanofluids (Fig. 5). It is well known that a higher thermal conductivity represents a better heat extraction ability. Moreover, Al-MWCNT hybrid nanofluids showed better spreadability (lower contact angle) compared to alumina nanofluids at a carbide insert surface. This may contribute to providing the maximum wetting area per unit liquid volume for the heat extraction of the cutting tool, which could lower the tool's temperature. Furthermore, a lower friction coefficient was observed during the tribology testing of the Al-MWCNT hybrid nanofluids using a pin-on-disc tribometer. This lower friction may cause reduction in the heat generation during the relative motion of the tool and the work-piece. Hence, the mixing

Table 7 Minimized response parameters for Alumina and Al-MWCNT nanofluid.

\begin{tabular}{|c|c|c|c|c|c|c|c|}
\hline \multirow[t]{2}{*}{ Nanofluid } & \multirow{2}{*}{ Response parameter } & \multirow{2}{*}{ Goal } & \multicolumn{4}{|c|}{ Input variables } & \multirow{2}{*}{$\begin{array}{l}\text { Minimized } \\
\text { response } \\
\text { value }\end{array}$} \\
\hline & & & $v(\mathrm{~m} / \mathrm{min})$ & $f(\mathrm{~mm} / \mathrm{rev})$ & $d(\mathrm{~mm})$ & np (vol\%) & \\
\hline \multirow{2}{*}{$\begin{array}{c}\mathrm{Al}_{2} \mathrm{O}_{3} \\
\text { nanofluid }\end{array}$} & Nodal temperature $\left(T /{ }^{\circ} \mathrm{C}\right)$ & Minimize & 60 & 0.082 & 0.6 & 1.15 & 81.29 \\
\hline & Tool flank wear $(\mathrm{VB} / \mu \mathrm{m})$ & Minimize & 90 & 0.08 & 0.6 & 1.24 & 64.4 \\
\hline \multirow{2}{*}{$\begin{array}{c}\text { Al-MWCNT } \\
\text { nanofluid }\end{array}$} & Nodal temperature $\left(T /{ }^{\circ} \mathrm{C}\right)$ & Minimize & 61.56 & 0.082 & 0.61 & 1.19 & 58.9 \\
\hline & Tool flank wear $(\mathrm{VB} / \mu \mathrm{m})$ & Minimize & 69.1 & 0.08 & 0.64 & 1.08 & 56.25 \\
\hline
\end{tabular}

Table 8 Responses of validation experiments for A12O3 and Al-MWCNT nanofluid.

\begin{tabular}{|c|c|c|c|c|c|c|c|c|}
\hline Nanofluid type & $\begin{array}{l}\text { Response } \\
\text { parameter }\end{array}$ & Test run & $v(\mathrm{~m} / \mathrm{min})$ & $f(\mathrm{~mm} / \mathrm{rev})$ & $d(\mathrm{~mm})$ & np (vol\%) & Experimental value & Average \\
\hline \multirow{6}{*}{$\begin{array}{c}\mathrm{Al}_{2} \mathrm{O}_{3} \\
\text { nanofluid }\end{array}$} & \multirow{3}{*}{$T\left({ }^{\circ} \mathrm{C}\right)$} & 1 & \multirow{3}{*}{60} & \multirow{3}{*}{0.082} & \multirow{3}{*}{0.6} & \multirow{3}{*}{1.15} & 85.89 & \multirow{3}{*}{83.53} \\
\hline & & 2 & & & & & 79.53 & \\
\hline & & 3 & & & & & 85.19 & \\
\hline & \multirow{3}{*}{$\mathrm{VB}(\mu \mathrm{m})$} & 1 & \multirow{3}{*}{90} & \multirow{3}{*}{0.08} & \multirow{3}{*}{0.6} & \multirow{3}{*}{1.24} & 65.43 & \multirow{3}{*}{65.39} \\
\hline & & 2 & & & & & 64.86 & \\
\hline & & 3 & & & & & 65.88 & \\
\hline \multirow{6}{*}{$\begin{array}{c}\text { Al-MWCNT } \\
\text { hybrid } \\
\text { nanofluid }\end{array}$} & \multirow{3}{*}{$T\left({ }^{\circ} \mathrm{C}\right)$} & 1 & \multirow{3}{*}{61.56} & \multirow{3}{*}{0.08} & \multirow{3}{*}{0.62} & \multirow{3}{*}{1.19} & 60.89 & \multirow{3}{*}{60.67} \\
\hline & & 2 & & & & & 59.94 & \\
\hline & & 3 & & & & & 61.18 & \\
\hline & \multirow{3}{*}{$\mathrm{VB}(\mu \mathrm{m})$} & 1 & \multirow{3}{*}{69.1} & \multirow{3}{*}{0.08} & \multirow{3}{*}{0.64} & \multirow{3}{*}{1.08} & 57.95 & \multirow{3}{*}{58.16} \\
\hline & & 2 & & & & & 57.34 & \\
\hline & & 3 & & & & & 59.19 & \\
\hline
\end{tabular}


of MWCNT with alumina may improve the heat extraction and lubricating properties compared to the alumina nanofluids. The obtained results are in good agreement with previous investigations [24-26].

\subsection{Tool flank wear}

Figure 13 shows micrographs of the tool flank wear at 3 volumetric concentrations $(0.25,0.75$, and $1.25 \mathrm{vol} \%)$ of alumina and Al-MWCNT nanofluids. It was found that the application of Al-MWCNT hybrid nanofluids recorded lower tool wear compared to alumina based nanofluids. Also, the increase of nanoparticle concentration reduced the tool flank wear possibly due to the reduced nodal temperature. The temperature generated at primary and secondary shear zone was primarily responsible for the tool wear. In the case of turning with Al-MWCNT hybrid nanofluids the tool edge retained its hardness for longer machining time due to a lower nodal temperature and thus partially reduced the flank wear compared to the alumina nanofluids.

It is known that the presence of alumina nanoparticles in cutting fluids generates ball bearing effect between the sliding surfaces [33,34]. Figure 14 illustrates the ball bearing effect of nanoparticles present in the cutting fluid. It was found that the blending of MWCNT with alumina nanoparticles has further reduced the friction coefficient between sliding surfaces due to a synergic effect of the hybrid nanoparticles and an improved performance of the hybrid nanofluids. The weak structure of MWCNT easily exfoliated due to the shearing action of the chip over the tool surface. This led to the formation of thin tribo-films between the sliding surfaces [33, 35]. Moreover, the thickness of the films and their effect was enhanced by the presence of higher number of nanoparticles at higher concentrations. Therefore, a reduction in the friction coefficient (Fig. 8) and in the wear (Fig. 9) was observed with hybrid nanofluids over the monotype alumina-based nanofluids. The tribology testing results show the mechanism of nanofluid behavior between the sliding surfaces (Fig. 14). The lower friction force due to the presence of MWCNT nanoparticles reduced the cutting force as well as the nodal temperature. Moreover, the hybrid nanofluids extracted the heat from the tool at a higher

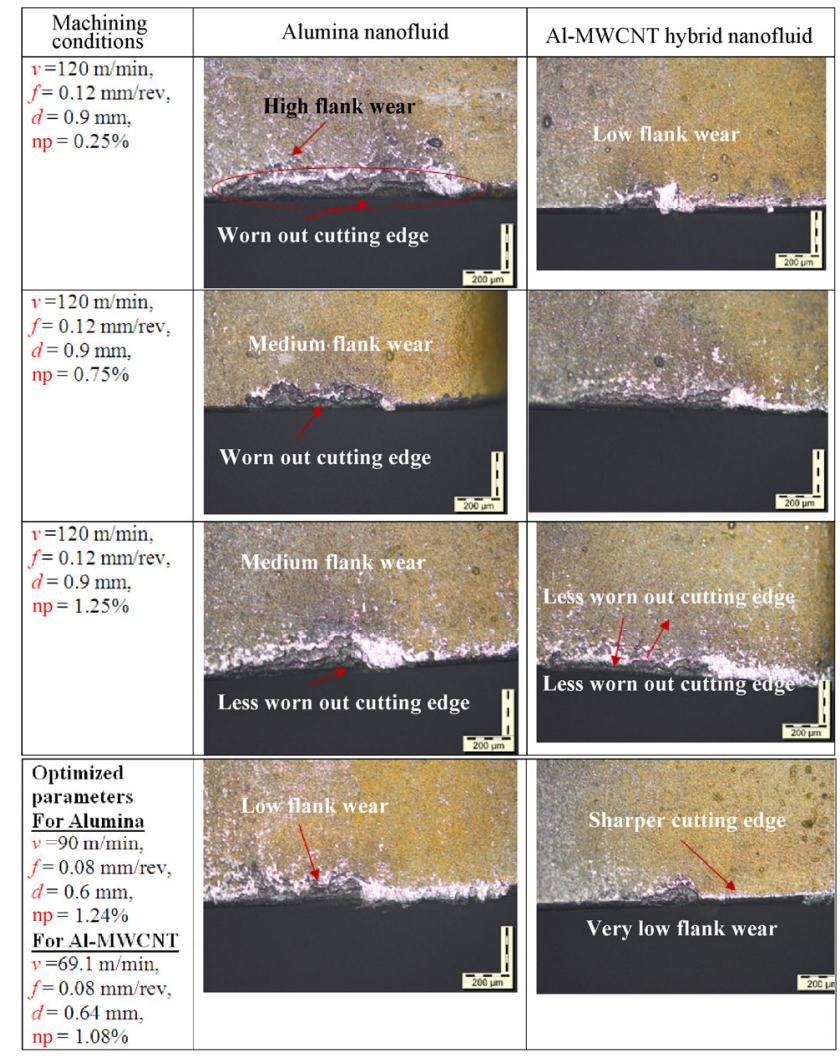

Fig. 13 Microscopic photographs of tool flank wear with alumina nanofluids and Al-MWCNT hybrid nanofluids at $v=120 \mathrm{~m} / \mathrm{min}$, $f=0.12 \mathrm{~mm} / \mathrm{rev}, d=0.9 \mathrm{~mm}$ and at optimized process parameters, respectively.

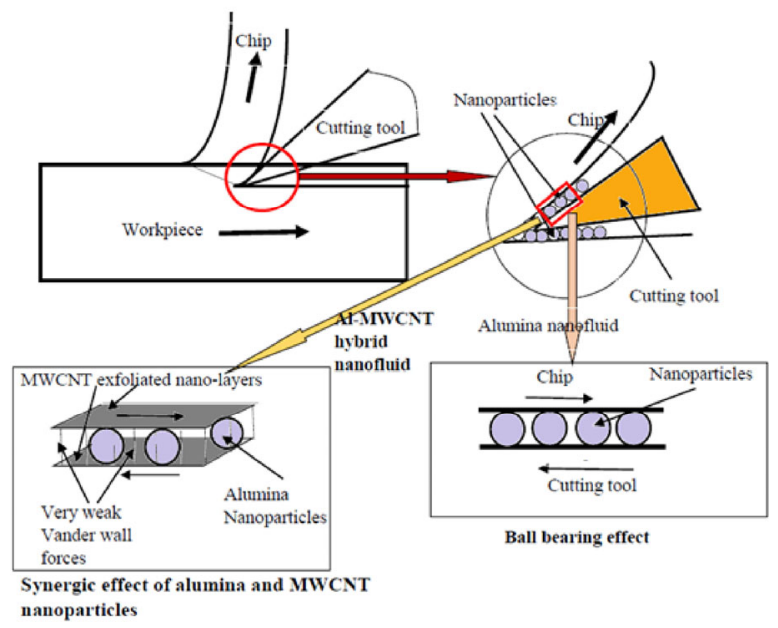

Fig. 14 Synergic effect of alumina/MWCNT hybrid nanoparticles during relative motion between the sliding surfaces.

rate and retained the hardness for longer periods because of their higher spreadability (wettability) at the tool surface and superior thermal conductivity compared to the alumina nanofluids. 


\section{Conclusions}

A hybrid nanocutting fluid with improved thermal and tribological properties was developed from blending MWCNT with alumina-based nanofluids in fixed volumetric proportions (10:90). The performance of the alumina-MWCNT hybrid nanolubricants as cutting fluids in turning operation under MQL technique in terms of tool flank wear and nodal temperature was compared to the alumina-based monotype lubricants. The following conclusions were drawn:

1. The mixing of MWCNT with alumina nanofluids enhanced the thermal conductivity $(\sim 2.6 \%)$ with the increase of nanoparticle concentration.

2. Testing of pin-on-disc tribometer of Al-MWCNT hybrid nanofluids showed lower friction coefficient $(\sim 0.09)$ compared to alumina nanofluids $(\sim 0.18)$.

3. The smallest contact angle (wettability) of Al-MWCNT and alumina nanofluids was recorded at $39.5^{\circ}(1.25 \mathrm{vol} \%)$ and $41.9^{\circ}(1.0 \mathrm{vol} \%)$, respectively, suggesting that the mixing of MWCNT with alumina improves the spreadability.

4. A significant reduction of $27.36 \%$ in the nodal temperature was achieved for Al-MWCNT hybrid nanofluids compared to alumina nanolubricants.

5. The use of Al-MWCNT hybrid nanofluids reduced the tool flank wear by $11 \%$ compared to alumina nanolubricants.

6. The hybridization of two different nanofluids improved their tribological properties, demonstrating the feasibility of their use as lubricant/cutting fluids. The optimized nanoparticle concentration ( 1.08 vol\%) of the Al-MWCNT hybrid nanofluids yielded the lowest tool flank wear making them potential candidates for turning of AISI 304 stainless steel.

So far, researchers have focused on lubricants containing monotype nanoparticles. To conclude, in this study we found that the mixing of MWCNT with alumina in a fixed volumetric ratio (10:90) improved its tribological and thermophysical properties. The optimization of the mixing ratio may additionally enhance these properties. Future studies on the optimization of the nanoparticle volume fraction, shape, and size may contribute to developing nanolubricants with improved tribological properties for the machining of hard-to-cut materials.
Open Access: The articles published in this journal are distributed under the terms of the Creative Commons Attribution 4.0 International License (http://creativecommons.org/licenses/by/4.0/), which permits unrestricted use, distribution, and reproduction in any medium, provided you give appropriate credit to the original author(s) and the source, provide a link to the Creative Commons license, and indicate if changes were made.

\section{References}

[1] Maruda R, Legutko S, Krolczyk G. Influence of minimum quantity cooling lubrication (MQCL) on chip formation zone factors and shearing force in turning AISI 1045 steel. Applied Mechanics and Materials 657: 43-47 (2014)

[2] Attanasio, Gelfi M, Giardini C, Remino C. Minimal quantity lubrication in turning: Effect on tool wear. Wear 260: 333338 (2006)

[3] Maruda R, Legutko S, Krolczyk G. Effect of minimum quantity cooling lubrication (MQCL) on chip morphology and surface roughness in turning low carbon steels. Applied Mechanics and Materials 657: 38-42 (2014)

[4] Cantero J L, lvarez J D, lez M H M, Marı'n N C. Analysis of tool wear patterns in finishing turning of Inconel 718. Wear 297: 885-894 (2013)

[5] Klocke F, Settineri L, Lung D, Priarone P C, Arft M. High performance cutting of gamma titanium aluminides: Influence of lubricoolant strategy on tool wear and surface integrity. Wear 302: 1136-1144 (2013)

[6] Maruda R W, Krolczyk G M, Feldshtein E, Nieslony P, Tyliszczak B, Pusavec F. Tool wear characterizations in finish turning of AISI 1045 carbon steel for MQCL conditions. Wear 372-373: 54-67 (2017)

[7] Sartori S, Ghiotti A, Bruschi S. Hybrid lubricating/cooling strategies to reduce the tool wear in finishing turning of difficult-to-cut alloys. Wear 376-377: 107-114 (2017)

[8] Sharma A K, Tiwari A K, Dixit A R, Singh R K. Novel uses of alumina- $\mathrm{MoS}_{2}$ hybrid nanoparticle enriched cutting fluid in hard turning of AISI 304 steel. Journal of Manufacturing Processes 30: 467-482 (2017)

[9] Sharma A K, Tiwari A K, Dixit A R, Singh R K. Investigation into performance of $\mathrm{SiO}_{2}$ nanoparticle based cutting fluid in machining process. Materials Today: Proceedings 4: 133141 (2017)

[10] Tiwari A K, Ghosh P, Sarkar J. Investigation of thermal conductivity and viscosity of nanofluids. Journal of Environmental Research and Development 7(2): 768-777 (2012) 
[11] Vajjha R S, Das D K. A review and analysis on influence of temperature and concentration of nanofluids on thermophysical properties, heat transfer and pumping power. International Journal of Heat and Mass Transfer 55: 40634078 (2012)

[12] Yang Y. Carbon nanofluids for lubricant application. PhD Thesis. University of Kentucky, United States, 2006.

[13] Choi S U S, Zhang Z G, Yu W, Lockwood F E, Grulke E A. Anomalous thermal conductivity enhancement in nanotube suspensions. Applied Physics Letters 79(14): 2252-2254 (2001)

[14] Sharma A K, Tiwari A K, Dixit A R. Progress of nanofluid application in machining: A review. Materials and Manufacturing Processes 30(7): 813-828 (2015)

[15] Lee C G, Hwang Y J, Choi Y M, Lee J K, Choi C, Oh J M. A study on the tribological characteristics of graphite nano lubricants. International Journal of Precision Engineering and Manufacturing 10(1): 85-90 (2009)

[16] Reddy N S K, Rao P V. Experimental investigation to study the effect of solid lubricants on cutting forces and surface quality in end milling. International Journal of Machine Tools and Manufacturing 46: 189-198 (2006).

[17] Kaynak Y, Karaca H E, Noebe R D, Jawahir I S. Tool-wear analysis in cryogenic machining of NiTi shape memory alloys: A comparison of tool-wear performance with dry and MQL machining. Wear 306: 51-63 (2013)

[18] Singh R K, Sharma A K, Dixit A R, Tiwari A K, Pramanik A, Mandal A. Performance evaluation of alumina-graphene hybrid nano-cutting fluid in hard turning. Journal of Cleaner Production, doi:10.1016/j.jclepro.2017.06.104 (2017)

[19] Amrita M, Srikant R R, Sitaramaraju A V. Performance evaluation of nanographite-based cutting fluid in machining process. Materials and Manufacturing Processes 29: 600-605 (2014)

[20] Yasar H S, Heris H Z, Shanbedi M. Influence of soluble oil-based $\mathrm{TiO}_{2}$ nanofluid on heat transfer performance of cutting fluid. Tribology International 112: 147-154 (2017)

[21] Parás L P, Tijerina J T, Garza L, Cortés D M, Michalczewski R, Lapray C. Effect of $\mathrm{CuO}$ and $\mathrm{Al}_{2} \mathrm{O}_{3}$ nanoparticle additives on the tribological behavior of fully formulated oils. Wear 332-333: 1256-1261 (2015)

[22] Roy S, Ghosh A. High speed turning of AISI 4140 steel using nanofluid through twin jet SQL system. In ASME International Manufacturing Science and Engineering Conference, Wisconsin, Madison, June 10-14, 2013.

[23] Jingxuan G, Gary C B, David J S, Qian Z, Scott B J. Tribological properties of $\mathrm{ZnO}$ and $\mathrm{WS}_{2}$ nanofluids using different surfactants. Wear 382-383: 8-14 (2017)
[24] Sarkar J, Ghosh P. A review on hybrid nanofluids: Recent research, development and applications. Renewable and Sustainable Energy Reviews 43: 164-177 (2015)

[25] Tanshen M R, Lee S, Kim J, Kang D, Noh J, Chung H, Jeong $\mathrm{H}$, Huh S. Pressure distribution inside oscillating heat pipe charged with aqueous $\mathrm{Al}_{2} \mathrm{O}_{3}$ nanoparticles, MWCNTs and their hybrid. Journal of Central South University 21: 2341-2348 (2014)

[26] Nine M J, Batmunkh M, Kim J H, Chung H S, Jeong H M. Investigation of $\mathrm{Al}_{2} \mathrm{O}_{3}$-MWCNTs hybrid dispersion in water and their thermal characterization. Journal of Nanoscience and Nanotechnology 12: 4553-4559 (2012)

[27] Ahammed N, Asirvatham L G, Wongwises S. Entropy generation analysis of graphene-alumina hybrid nanofluid in multiport mini channel heat exchanger coupled with thermoelectric. International Journal of Heat and Mass Transfer 103: 1084-1097 (2016)

[28] Zhang Y, Li C, Jia D, Li B, Wang Y, Yang M, Hou Y, Zhang X. Experimental study on the effect of nanoparticle concentration on the lubricating property of nanofluids for MQL grinding of Ni-based alloy. Journal of Materials Processing Technology 232: 100-115 (2016)

[29] Abbasi S M, Rashidi A, Nemati A, Arzani K. The effect of functionalization method on the stability and the thermal conductivity of nanofluid hybrids of carbon nanotubes/gamma alumina. Ceramic International 39: 3885-3891 (2013)

[30] Kanthavel K, Sumesh K, Saravanakumar P. Study of tribological properties on $\mathrm{Al} / \mathrm{Al}_{2} \mathrm{O}_{3} / \mathrm{MoS}_{2}$ hybrid composite processed by powder metallurgy. Alexandria Engineering Journal 55: 13-17 (2016)

[31] Khandekar S, Sankar M R, Agnihotri V, Ramkumar J. Nano-cutting fluid for enhancement of metal cutting performance. materials and manufacturing processes 27 : 963-967 (2012)

[32] Wasan D, Nikolov A, Kondiparty K. The wetting and spreading of nanofluids on solids: Role of the structural disjoining pressure. Current Opinion in Colloid \& Interface Science 16: 344-349 (2011)

[33] Park K H, Ewald B, Kwon P Y. Effect of nano-enhanced lubricant in minimum quantity lubrication balling milling. Journal of Tribology 133: 31803 (2011)

[34] Sharma A K, Tiwari A K, Dixit A R. Improved machining performance with nanoparticle enriched cutting fluids under minimum quantity lubrication (MQL) technique: A review. Materials today: Proceedings 2: 3545-3551 (2015)

[35] Dai W, Kheireddin B, Gao H, Liang H. Roles of nanoparticles in oil lubrication. Tribology International 102: 88-98 (2016) 


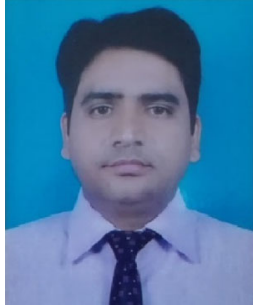

Anuj Kumar SHARMA. He received his PhD degree in Mechanical Engineering in 2017 from Indian Institute of Technology (ISM) Dhanbad India. Presently he is associated with

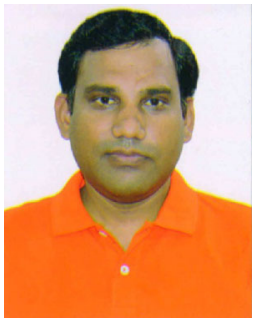

Jitendra Kumar KATIYAR. He received his $\mathrm{PhD}$ degree in Mechanical Engineering from Indian Institute of Technology Kanpur India in 2017. Presently he is associated with SRM

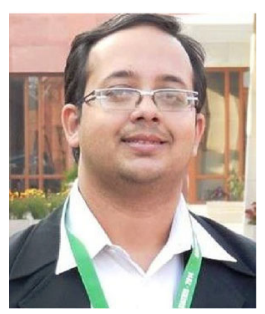

Shubrajit BHAUMIK. He received his M.Tech degree from SRM University Tamil Nadu India. Presently he is working as an Assistant Professor in the Department of Mechanical Engineering,

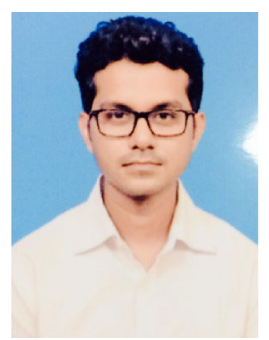

Sandipan ROY. He received his $\mathrm{PhD}$ degree in Aerospace Engineering and Applied Mechanics in 2017 from Indian Institute of Engineering Science and Technology Shibpur
SRM Institute of Science and Technology Tamil Nadu as Research Assistant Professor. His core areas of research include machining, machining tribology, nano-cutting fluids and minimum quantity lubrication (MQL) machining.

Institute of Science and Technology Tamil Nadu as Research Assistant Professor. His research interests are surface coatings, lubrication tribology, polymer tribology, micro/nano tribology, and engineering materials

SRM Institute of Science and Technology. He has been awarded with best presentation award in Malaysian International Tribology Conference 2015. His research interests are nano-lubricants, texturing, polymer tribology, etc., and is working closely with many industries in the field of tribology.

India. Presently he is associated with SRM Institute of Science and Technology Tamil Nadu as Research Assistant Professor. His core areas of research include bio-materials, bio-tribology, biomechanics, and finite element analysis. 